\title{
A MONOGAMIA EM KAREN HORNEY: CONSIDERAÇÕES ACERCA DAS CONSTRUÇ̃̃ES PSICANALÍTICAS SOBRE FEMINILIDADE
}

\author{
MONOGAMY IN KAREN HORNEY: CONSIDERATIONS ON THE PSYCHOANALYTIC \\ CONSTRUCTIONS OF FEMININITY
}
LA MONOGAMIA EN KAREN HORNEY: CONSIDERACIONES SOBRE LAS CONSTRUCCIONES PSICOANALÍTICAS DE LA FEMINIDAD

Patrícia Mafra de Amorim*

Fábio Roberto Rodrigues Belo

\begin{abstract}
RESUMO
Este trabalho se propõe a investigar as contribuições da psicanalista Karen Horney para a compreensão dos relacionamentos amorosos. A autora nos pareceu uma boa representante do que Laplanche sinaliza como recalques presentes na teoria psicanalítica. Investigamos o desenrolar da psicologia do amor de Horney, com base na metodologia laplancheana de análise de textos psicanalíticos, buscando apontar seus méritos e deméritos na construção de uma teoria psicanalítica que é comprometida com as consequências políticas de suas elaborações. A monogamia, instituição hegemônica e que tende a ser interpretada como natural em nossa sociedade ocidental, parece-nos o campo ideal para a discussão proposta pela autora sobre o lugar designado às mulheres. Traçaremos, portanto, um raio vetor sobre o tema, observando as diferentes formas pelas quais se repete na obra da autora. Colocando em questão a forma como são constituídos os relacionamentos amorosos, fazse necessária a abordagem das questóes identificatórias e de gênero que os perpassam.
\end{abstract}

Palavras-chave: Karen Horney. Monogamia. Recalque. Gênero. Sexual.

\begin{abstract}
This study aims to investigate contributions from the psychoanalyst Karen Horney to the understanding of love relationships. We reckon the author seems to be a good representative of what Laplanche points out as present suppressions in psychoanalytic theory. We investigated the flow of Karen Horney's psychology of love, based on Laplanche's methodology
\end{abstract}

\footnotetext{
Texto recebido em 30 de setembro de 2016 e aprovado para publicação em 9 de outubro de 2017.

*Doutoranda no Programa de Psicologia Clínica na Universidade de São Paulo (USP), bolsista CAPES.

"Professor adjunto no Departamento de Psicologia na Faculdade de Filosofia e Ciências Humanas da Universidade Federal de Minas Gerais (UFMG).
} 
for the analysis of psychoanalytic texts, willing to identify their merits and demerits in the construction of a psychoanalytic theory that is committed to the political consequences of its elaborations. Monogamy, hegemonic institution that tends to be interpreted as natural in our Western society, seems the ideal field for the discussion proposed by the author on the place assigned to women. Therefore, we shall trace a vector ray about the theme, observing the different forms through which it repeats itself in the author's work. Arguing how romantic relationships are made up, it is necessary to approach the issues of identification and gender, which pervade such relationships.

Keywords: Karen Horney. Monogamy. Surppression. Gender. Sexual.

\section{RESUMEN}

Este estudio tiene como objetivo investigar las contribuciones de la psicoanalista Karen Horney a la comprensión de las relaciones de amor. La autora parecía una buena representante de lo que Laplanche señala como represiones presentes en la teoría psicoanalítica. Investigamos la conducta de Horney en la psicología del amor, a partir de la metodología laplancheana de análisis de textos psicoanalíticos, buscando identificar sus méritos y deméritos en la construcción de una teoría psicoanalítica que está comprometida con las consecuencias políticas de sus elaboraciones. La monogamia, institución hegemónica y que tiende a ser interpretada como natural en nuestra sociedad occidental, parece el campo ideal para el debate propuesto por la autora acerca del lugar asignado a las mujeres. Delinearemos, por lo tanto, un rayo vector sobre el tema, considerando las diferentes maneras a través de las cuales se repite en la obra de la autora. Para cuestionar cómo se hacen las relaciones románticas, es necesario abordar las cuestiones identificatorias y de género que las permean.

Palabras clave: Karen Horney. Monogamia. Represión. Género. Sexual.

\section{APRESENTAÇÃO}

$\mathrm{H}$ istoricamente, os estudiosos da Psicanálise vêm elegendo determinados autores para consagrar a continuidade desse campo do saber, enquanto relega outros ao profundo esquecimento. No entanto, ao tomar conhecimento da teoria analítica, descobrimos que nenhuma escolha, seja ela de objetos de amor ou de autores a serem lidos, está livre da persistente intervenção do inconsciente. É notável que Karen Horney, psicanalista alemã, contemporânea de Freud, tenha sido mais reconhecida por seu trabalho nos Estados Unidos, a 
partir de 1932 até sua morte, em 1952 (Reyes, 2002), do que na Europa, onde completou seus estudos em Psiquiatria e Psicanálise em 1913.

Nascida em 1885, na cidade de Hamburgo, na Alemanha, Horney se formou em Medicina pela Universidade de Berlim, tendo tido contato com a Psicanálise mediante seus estudos em Neurologia e Psiquiatria. Em 1919, já possuía sua clínica particular, tendo sido importante membro do Instituto Psicanalítico de Berlim, entre 1918 e 1932, quando se mudou para os Estados Unidos. Os primeiros ensaios de Horney tratam principalmente de questôes referentes à constituição da feminilidade. De acordo com Paris (1994), devido ao fato de esses primeiros trabalhos confrontarem as concepçôes freudianas de inveja do pênis, masoquismo e desenvolvimento feminino, promovendo grandes controvérsias, posteriormente tais ensaios foram esquecidos, uma vez que Freud e seus seguidores buscaram silenciar as disputas que foram levantadas.

Horney, a partir de seus trabalhos acerca da maternidade e do feminino, distanciou-se do freudismo, lançando mão de uma abordagem culturalista para embasar suas novas elaborações (Roudinesco \& Plon, 1998). A abordagem culturalista propõe "uma explicação para o homem que se fundamente na diferença e no relativismo, questionando o universalismo próprio dos grandes sistemas de pensamento oriundos da tradição do saber ocidental" (Roudinesco $\&$ Plon, 1998, p. 140). Essa corrente de pensamento é fundamentalmente norte-americana, tendo Horney desempenhado um papel importante para a disseminação de seu viés psicanalítico nos Estados Unidos (Kurzweill, 2000) ${ }^{1}$.

Neste artigo, abordaremos as críticas de Horney à teoria da feminilidade freudiana, tomando como modelo as elaborações da autora acerca das relações amorosas, mais especificamente suas colocações a respeito da monogamia. Tal escolha se justifica, a nosso ver, devido à extensão das teorizaçôes de Horney sobre a sexualidade feminina, sendo necessário um recorte que, ao mesmo tempo, seja representativo em termos teóricos e clínicos, a fim de que se compreendam os pontos de convergência e divergência dos autores, bem como as teorizações mais atuais sobre o tema.

A escolha de Freud e Horney se deu por questôes de cunho metodológico, já que tentaremos, por meio de uma "ortodoxia freudiana", como diria Laplanche (1992b, p. 37), observar como o tema da monogamia é abordado, seja como elemento explícito ou implícito, nas obras em questão, colocando no mesmo plano o insignificante e o que é constantemente repetido (Laplanche, 1978),

\footnotetext{
${ }^{1}$ Apesar de Adler ser reconhecido como o criador do enfoque culturalista, Karen Horney, Erich Fromm e Harry Stack Sullivan já desenvolviam trabalhos cuja característica central era a priorização da determinação sociocultural no desenvolvimento humano (Reyes, 2002).
} 
para que fiquem claras a quais funções, ou desejos inconscientes, a instituição monogâmica serviu nas obras dos referidos autores.

Retomar a obra de Freud é importante como ponto de partida para analisar como o tema da monogamia e questôes associadas a ele, como a feminilidade, originaram-se dentro das elaborações psicanalíticas, para então verificarmos algumas consequências dessas abordagens iniciais no desenvolvimento das teorizações sobre o assunto. Apresentaremos, portanto, as formas pelas quais as elaborações acerca do tema se desenvolveram na obra da psicanalista alemã Karen Horney. Buscamos expor as contribuições da autora em relação à dimensão conflitiva das escolhas amorosas bem como das constituições identitárias, sem deixar de apontar para os desvios presentes também em sua teorização.

Horney apresenta, em sua obra, reflexões importantes sobre a monogamia e assuntos relacionados a ela (Horney, 1926/1991, 1927/1991, 1932/1991)2.No entanto, como mostraremos, suas argumentações confrontavam, muitas vezes, as primeiras elaborações freudianas, o que supomos, juntamente com o fato de ser uma mulher em meio a uma prática majoritariamente masculina, levou ao recalcamento de suas contribuiçôes na História da Psicanálise. Dessa forma, buscamos analisar a obra de Horney no que diz respeito ao tema da monogamia e seu tangenciamento com as elaborações acerca da feminilidade.

Partiremos, para tanto, da concepção laplancheana de que o texto tem um conteúdo manifesto e um conteúdo latente (Laplanche, 1978), a fim de explicitar esses conteúdos na obra de Horney. Dessa forma, propomo-nos a colocar o arranjo monogâmico como objeto central de análise, tirando-o do lugar naturalizado ao que é comumente designado, investigando sob quais nuances ele aparece em meio às teorizações psicanalíticas, seja como detalhe ou tema principal.

Entendemos que, ao colocar em questão os relacionamentos amorosos, suas modalidades, sucessos e fracassos, faz-se fundamental uma compreensão aprofundada das questões de gênero e identificação que perpassam e afetam tais relacionamentos. Por isso, este estudo partirá da proposição de Laplanche (2015b), "O sexual é o resíduo inconsciente do recalque-simbolização do gênero pelo sexo" (p. 155), a qual discutiremos, com maior profundidade, mais adiante.

Os resultados que serão apresentados dizem respeito às consequências de colar a escolha objetal à identidade de gênero, sendo que optamos por apresentar interpretações que desvinculam tais dimensões do psiquismo, tomando por base as elaborações laplancheanas sobre gênero, sexo e sexual. Na tentativa de retomar e explicitar a prioridade do outro na constituição psíquica, aproximamos as

\footnotetext{
${ }^{2}$ A primeira data indica o ano de publicação da obra, e a segunda, a edição consultada pelo autor, a qual somente será pontuada na primeira citação da obra no texto. Nas seguintes, será registrada apenas a data de publicação original.
} 
elaborações horneyanas e a teoria da sedução generalizada, a fim de fazer a teoria psicanalítica trabalhar, no sentido de expandir cada vez mais o campo das interpretaçôes acerca do enlace amoroso, buscando dar continuidade ao movimento copernicano no campo dos estudos da constituição psíquica inaugurado por Freud (Laplanche, 1992a).

Tendo em vista o nível da exigência proposto por Laplanche (1978), que se situa a uma certa distância do conteúdo manifesto da obra, desconfiando de qualquer intervenção egoica no contexto da doutrina, buscamos nos ater à interpretação psicanalítica do objeto em questão, reconhecendo, como Horney o faz em determinados momentos, a dimensão pulsional da monogamia, que não deve ser considerada como uma saída melhor que qualquer outra.

\section{O DEBATE SOBRE A FEMINILIDADE}

Pode-se dizer que Freud, desde o início de sua obra, não elaborou uma teoria da diferença sexual. Aparentemente foi a evolução de sua teoria, com o acúmulo de descobertas, hipóteses e preconceitos, bem como de outros e, principalmente, outras analistas que o levaram, no fim da década de 1910 e início da de 1920, a discutir abertamente o problema da diferença sexual (Appignanesi \& Forrester, 2010).

Apesar de essa abordagem explícita do tema ser um pouco tardia, a questão das diferenças de gênero no desenvolvimento psíquico parecia já atormentar Freud desde os primórdios de suas elaborações (Valdivia, 1997). Já nas cartas a Fliess, Freud tentava precisar a questão da feminilidade, apresentando várias hipóteses que foram continuamente revistas durante sua teorização sobre o tema (Valdivia, 1997).

De acordo com Silva e Folberg (2008), os Três ensaios seriam o ponto a partir do qual se encontrariam as bases para o desenvolvimento da teoria da feminilidade freudiana. As autoras colocam o monismo sexual, apresentado naquele trabalho, como a primeira das teorias sexuais de Freud, sendo determinante para as elaborações sobre a feminilidade, visto que tem, em sua concepção, que o único órgão sexual reconhecido pela criança nos dois sexos é o masculino. Em outras palavras, a colocação da lógica fálica como estruturadora do psiquismo infantil.

Freud, em seus ensaios, aponta a existência do complexo de castração tanto nos meninos quanto nas meninas, introduzindo ainda o conceito de inveja do pênis presente nestas últimas, como foco central de conflito no desenvolvimento psíquico destas. No entanto coloca que não há distinção entre o psiquismo masculino e o feminino até a puberdade, mantendo a concepção do clitóris 
como órgão fálico e desconsiderando a vagina como fonte de excitações (Silva \& Folberg, 2008). Apenas em 1914, em Uma introdução ao narcisismo, ao falar sobre a instauração do superego, que estabelecerá uma relação mais direta entre o complexo de Édipo e o complexo de castração, sendo que os apontamentos em relação às diferenças no desenvolvimento psíquico de meninos e meninas virão apenas em 1924, em $A$ dissolução do complexo de Édipo (Silva \& Folberg, 2008).

Como colocam Silva e Folberg (2008):

A concepção de que a verdadeira organização genital está ausente até a puberdade é mantida. Para o menino, o declínio do complexo de Édipo se realizará sob ação do complexo de castração, vivendo um conflito entre seus desejos libidinosos que dirige à mãe (num Édipo positivo) e o interesse narcísico que dirige para o pênis, prevalecendo normalmente o segundo caso. Na menina, o complexo de castração despertado pela visão do pênis nos meninos a levará a um sentimento de inferioridade e a querer compensar sua falta pela inveja do pênis. [.. .] Freud discutiu muito mais plenamente esta citação em seus trabalhos sobre a distinção anatômica dos sexos em 1925 e em 1931, quando falou da sexualidade feminina. Em ambos, fornece informaçôes muito diferentes sobre o complexo de Édipo na menina, o que mostra o quanto ele refazia constantemente suas consideraçōes a respeito da questão (p. 51).

As autoras ainda afirmam que, em seus últimos escritos sobre a feminilidade, Freud ressalta o papel do complexo de castração no desenvolvimento da menina, levantando ainda a questão da bissexualidade e a forma pela qual a menina faz as transferências, primeiro de investimento do clitóris para a vagina, e de objeto de amor, da mãe para o pai (Silva \& Folberg, 2008).

Em suas críticas à teoria freudiana a respeito do debate sobre a mulher, Horney questiona pontos nodais da teoria, como o papel central da inveja do pênis na constituição feminina. Appignanesi e Forrester (2010) colocam, inclusive, que é ela quem estabelece a pauta da crítica feminista a Freud, ao demonstrar, de maneira contundente, como a teoria psicanalítica sobre a feminilidade aproximase da teoria sexual infantil dos meninos sobre as meninas. No artigo de 1926, $A$ fuga da feminilidade, Horney põe lado a lado as concepções infantis acerca das diferenças sexuais e as da teoria da feminilidade, denunciando como Freud, e outros psicanalistas, hipostasiam a concepção fálica da existência de dois tipos de seres, os que possuem um pênis e os castrados.

De acordo com Garrison (1981), Horney publica seu primeiro trabalho sobre a psicologia feminina em 1923 (A gênese do complexo de castração nas mulheres), em resposta ao artigo de 1922, de Karl Abraham, seu antigo analista, Manifestações do complexo de castração feminino. Nesse trabalho, Abraham parece interessado em dar uma explicação psicológica aos movimentos de mulheres de luta por igualdade que despontam na época, atribuindo-os à ausência de pênis 
nas mulheres, uma insatisfação com seu sexo e desejos de vingança. Horney (1923/1991), ainda bastante influenciada pelo pensamento de Freud, por sua vez, questiona tal afirmação, partindo da experiência clínica com mulheres, em que o complexo de castração é evidente, ao colocar que a inveja do pênis não está diretamente relacionada com a negação da feminilidade.

Já no artigo de 1933, A negação da vagina (Horney 1933/1991), ela, já mais próxima à concepção culturalista, faz uma crítica explícita à teoria freudiana, questionando a centralidade da inveja do pênis na constituição do psiquismo das mulheres e contrapondo-a a um outro conceito, a inveja do útero, que desempenharia, de acordo com suas observaçôes, um papel mais importante no desenvolvimento sexual dos homens do que era reconhecido até então. Nesse artigo, a autora traz argumentos sólidos que desconstroem a ideia clássica de que a vagina é desconhecida até a puberdade, tanto por parte dos meninos como das meninas, questionando o fato de que as identidades de gênero só são verdadeiramente colocadas após a puberdade. Ela coloca, baseada em suas observaçôes clínicas e de estudos de ginecologistas, que:

Embora Freud não afirme expressamente, é evidente que, se a vagina permanece "desconhecida", este é um dos argumentos mais fortes a favor da hipótese de inveja primária do pênis biologicamente determinada nas meninas ou da sua organização fálica original. Se não existissem sensações ou anseios vaginais e toda a libido estivesse concentrada no clitóris, falicamente concebido, poderíamos compreender como as meninas, por falta de fonte específica própria de prazer ou desejos especificamente femininos, seriam levadas a concentrar toda a atenção no clitóris, a compará-lo com o pênis do menino e depois, comprovada sua desvantagem nesta comparação, a sentirem-se definitivamente menosprezadas. Se, por outro lado, como penso, a menina experimenta desde o início sensaçóes vaginais e impulsos correspondentes, deve ter, desde o princípio, forte senso do caráter específico do próprio papel sexual, e é difícil responsabilizar a inveja primária do pênis na intensidade postulada por Freud (Horney, 1933, p. 158).

Essa proposição da autora deixa claro que a hipótese do desconhecimento da vagina é, na realidade, a negação de sua existência e, consequentemente, de sua importância na constituição psíquica das mulheres. Horney (1933) aponta para o recalcamento das sensaçóes vaginais pelas mulheres que se apresentam para a análise, mas mantém a posição de investigação analítica, atentando-se para os sinais desse recalcamento, como os distúrbios sexuais presentes nas mulheres e mesmo as fantasias de estupro, as quais indicam forte angústia diante da consciência prévia da cavidade vaginal. Pode-se dizer que, ao comparar o clitóris com o pênis, as mulheres encontram-se em "desvantagem anatômica", e assim permanecem ao negar-se a existência de outra fonte de prazer e angústia, tão importante, ou mais, do que o órgão fálico. 
A autora, como outras psicanalistas, tem suas contribuições para a teoria psicanalítica colocadas em um plano subalterno, talvez por ser uma mulher em um meio dominado por homens, algo que ela mesma parece já se atentar em seu artigo A fuga da feminilidade (Horney, 1926). Talvez mesmo por exprimir opiniôes e elaborar conceitos tão polêmicos e conflitivos com a teoria clássica de Freud, como a inveja do útero, a negação da vagina e o enfoque culturalista que dá às suas interpretaçôes.

Percebemos que o debate sobre a feminilidade, longe de ter sido dado como encerrado, é de extrema importância para o desenvolvimento da teoria psicanalítica, sendo fonte de inúmeras discordâncias e polêmicas que estão para além das elaborações estritamente teóricas, mas que têm consequências clínicas e políticas que não podem ser ignoradas. Nas próximas seçôes, abordaremos algumas dessas consequências, tendo como foco os relacionamentos amorosos, campo no qual os conflitos oriundos da sexualidade humana parecem ter expressão especialmente forte.

\section{A PSICOLOGIA DO AMOR, DE KAREN HORNEY}

Nesta seção, buscaremos expor como Horney discute a questão da centralidade da monogamia na sociedade ocidental, como pacto hegemônico de relacionamento amoroso. A autora defende a hipótese de que a ausência de estudos nesse campo se deve a recalcamentos pelo fato de essa instituição nos remeter a conflitos demasiado próximos às nossas experiências mais íntimas, além de ser uma instituição social, dificultando, assim, sua contestação (Horney, 1927). Ela aborda o tema de maneira bastante explícita, colocando, inclusive, a importância de indagarmo-nos sobre a monogamia, uma vez que, em termos práticos, há uma grande frequência de conflitos matrimoniais expostos em situações de análise, e, mesmo em termos teóricos, já que, de acordo com a autora, dificilmente há outra situação tão íntima e tão vinculada às experiências infantis como o casamento.

Percebe-se que, em vários artigos do livro Psicologia feminina (Horney, 1927), o qual se configura como uma reunião dos ensaios de Horney sobre a feminilidade, questôes referentes ao casamento, à monogamia e ao amor emergem como situações culturais que contribuem para a manutenção de determinada identidade feminina, estando, portanto, diretamente relacionadas a questões da feminilidade, como o estilo de vinculação e a maternidade. Percebemos que, nos primeiros textos, Horney mantinha suas elaboraçôes teóricas com uma forte 
vinculação ao pensamento freudiano, mas, gradualmente, adota interpretações mais culturalistas para dar conta de suas observaçôes clínicas, criticando, inclusive, algumas concepções biologizantes de Freud.

Em Oidealmonogâmico, Horney (1927) aborda como as questôes inconscientes são condicionantes da opção pela monogamia bem como do tipo de escolha de parceiros. Ela afirma:

O que nos leva ao casamento é nada mais nada menos do que a expectativa de que encontraremos nele a satisfação de todos os antigos desejos surgidos na situação edipiana da infância - o desejo de ser uma esposa para o pai, de tê-lo como nossa posse exclusiva e de lhe dar filhos. De passagem, posso dizer que, sabendo disso, tendemos a ser extremamente céticos quando ouvimos profetizar que a instituição do casamento está para acabar, embora admitamos que a qualquer momento a estrutura da sociedade afetará a forma desses eternos desejos. Portanto, a situação inicial do casamento está vergada sob o imenso peso dos desejos inconscientes (Horney, 1927, p. 82)

Concordando, portanto, com a psicologia do amor freudiana, Horney coloca que o marido ou a esposa são objetos de amor situados entre a repetição e a transferência: continuam relações amorosas arcaicas. A maternidade e a paternidade reais são parte dessa repetição e, visto que não realizam os ideais construídos a partir dos desejos infantis, levariam a problemas no casamento. Sempre haverá uma maior ou menor discrepância entre o objeto encontrado, a satisfação alcançada e os desejos sexuais inconscientes específicos (Horney, 1927). Essas colocações explicitam a concepção cindida e conflitiva do sujeito. Jamais seremos capazes de fazer uma escolha de objeto que não esteja comprometida com questôes inconscientes e, por consequência, que seja livre de conflitos.

Ainda em relação aos problemas comuns encontrados em relações monogâmicas, Horney (1932) demonstra como nossos desejos contraditórios podem levar a imensas frustrações, como a decepção, a desconfiança e a hostilidade nos relacionamentos, apontando a negação dessas contradições internas como uma defesa à ameaça que elas constituem às nossas personalidades e às nossas vidas. Tais contradiçóes, de acordo com Horney, aparecem, de forma mais explícita, no campo sexual, sendo lógico que se estendam aos relacionamentos, especialmente do tipo tão íntimo como o casamento. Dessa forma, torna-se comum a culpabilização do cônjuge por não conseguir cumprir as expectativas contraditórias de seu parceiro ou parceira. Há ainda as dificuldades resultantes de conflitos primitivos entre os sexos (gêneros) que, de acordo com a autora, persistem e interferem nos relacionamentos futuros. Como colocam Belo e Marzagão (2011): "Alguns traços dessas vivências iniciais [de amor primitivo] ficam marcados e afetarão o relacionamento posterior com o sexo oposto" (p. 
123).

Nota-se, no entanto, que, mesmo que Horney (1927) esteja atenta à dimensão cindida do sujeito, em alguns momentos, parece tomar o esquema narrativo edípico como uma realidade primária e marcadamente heteronormativa. Ela enfatiza que:

Embora o casamento represente a realização dos desejos infantis, estes podem ser satisfeitos desde que o desenvolvimento do sujeito lhe permita efetuar verdadeira identificaçăo com o papel de pai ou da mãe. Sempre que a revelação do complexo de Édipo partir desta norma fictícia, encontraremos o mesmo fenômeno: a pessoa em questão tende em alguns pontos fundamentais ao papel da criança na tríade pai, mãe e filho. Quando é este o caso, os desejos que surgem desta atitude instintiva não podem ser satisfeitos diretamente pelo casamento. [ . . . Para a criança, o objeto de amor está indissoluvelmente associado à ideia de algo proibido; mas o amor pelo marido ou pela mulher não é só permitido; assoma por trás dele a portentosa ideia do dever conjugal. A rivalidade (situação em que há uma terceira parte magoada) está excluída pela própria natureza do casamento monogâmico; o monopólio é privilégio concedido por lei (Horney, 1927, p. 87).

Considerar que os desejos infantis relacionados à posse de um dos progenitores podem ser satisfeitos, mesmo que diante de condições específicas, aparentemente denuncia uma posição horneyana acerca da presença de determinados roteiros inconscientes. Estes, por sua vez, poderiam limitar as respostas tradutivas dos sujeitos diante de alguns estímulos pulsionais, como os que são inoculados na criança pelas primeiras relações com seus cuidadores. Poderíamos pensar, no entanto, que essas observaçôes de Horney têm o mérito de explicitar algumas funções de apaziguamento que o contrato monogâmico traz, como a não rivalidade e a exclusividade.

Em Os problemas no casamento (Horney, 1932), a autora faz algumas considerações a respeito de a monogamia ser uma garantia contra os tormentos causados pelo ciúme, expondo que o ideal de fidelidade não é elementar, por não existir desde a infância, mas sim uma restrição pulsional. Nesse mesmo artigo, Horney questiona o fato de a exigência monogâmica recair preponderantemente sobre as mulheres, descartando a afirmação frequente de que homens têm tendências poligâmicas mais fortes que aquelas. Horney (1927) relembra as influências históricas e sociais (como a garantia da paternidade) da repressão da sexualidade feminina no desenvolvimento dessa exigência de fidelidade por parte das mulheres.

Horney, apesar de apresentar uma teoria crítica sobre os relacionamentos amorosos, considerando influências socioculturais, principalmente no que tangem ao gênero, muitas vezes, também recai em desvios ${ }^{3}$ com base em biologizaçôes

\footnotetext{
${ }^{3}$ Laplanche (1997), em suas investigaçôes sobre obra freudiana, chama de desvio o elemento teórico que "é originário do recuo,
} 
heteronormativas. Percebemos uma tendência da autora a aproximar-se das explicações biologizantes na tentativa de entender a suposta maior importância dada à relação sexual pelas mulheres a partir da possibilidade da gravidez (Horney, 1932) ${ }^{4}$. Colocando também que as mulheres permaneceriam, de maneira geral, mais vinculadas ao seu objeto de amor primitivo, no caso o pai, devido à não resolução do complexo de Édipo, tornando-se, portanto, mais fiéis que os homens.

Percebe-se que a autora, apesar de considerar não somente os fatores inconscientes da escolha de parceiros amorosos, também dá destaque às influências culturais presentes nessa escolha e na construção de ideais que ela representa. No entanto, Horney, em suas elaborações metapsicológicas acerca da monogamia, parece ater-se demasiadamente ao código edipiano, atribuindo novamente conteúdos às instâncias inconscientes, como veremos nesta seção.

No artigo já mencionado, O ideal monogâmico (Horney, 1927), ela coloca que, na situação do casamento, o superego é ameaçado pelo retorno da antiga proibição de incesto, associada ao parceiro dessa vez, levando aos mesmos resultados da relação entre bebê e cuidador, cuidadora, ou seja, os objetivos sexuais diretos são substituídos por uma atitude de afeição em que esses alvos são inibidos, ou recalcados. Como mecanismos para tolerar-se a relação conjugal, apesar da proibição do incesto, no que diz respeito à instância do id, a autora coloca as inibiçôes sexuais, de todos os tipos, desde a reserva sexual até a impotência ou frigidez. E, quanto ao ego, afirma que as tentativas de reafirmação ou justificação, como a negação do casamento, quando, por exemplo, as mulheres casadas assinam seus nomes de solteiras, ou, por outro lado, quando há a supervalorização do amor conjugal. Percebemos que a autora, na tentativa de explicitar sua hipótese sobre a compulsão à repetição na escolha de parceiros amorosos em contratos monogâmicos, recorre à teoria do complexo edípico de maneira bastante generalista, aparentando, assim como Freud, crer na origem filogenética dessas fantasias ditas originárias (Horney, 1927). Isso parece ficar claro no trecho de Os problemas no casamento (Horney, 1932):

Um dos insights básicos e provavelmente indiscutíveis que devemos a Freud diz que o amor e a paixão não aparecem pela primeira vez na puberdade, mas que a criancinha já é capaz de sentir, desejar e exigir apaixonadamente. Como seu espírito ainda não foi inibido e alquebrado, ela provavelmente é capaz de experimentar esses sentimentos em intensidade bastante diferente da que é possível para nós adultos. Se aceitarmos estes fatos e, além disso, a evidência de que nós, como qualquer animal, estamos sujeitos à grande lei da atração quase obrigatório, e que não deve ser reprovado a Freud, diante das consequências da prioridade do outro, na constituição [. . .] do ser humano sexual" (p. 13).

${ }^{4}$ Em suas teorizações posteriores, Horney questionará as biologizações freudianas, oferecendo respostas culturais aos elementos que Freud considerava naturais, no entanto percebemos que, nesse momento de sua obra, a autora comete alguns desvios, atendo-se a essas concepções clássicas da constituição psíquica. 
heterossexual, então o polêmico complexo de Édipo postulado por Freud, como fase do desenvolvimento pela qual todas as crianças passam, não nos parece tão estranho e peculiar (pp. 122-123, grifo nosso).

Percebe-se que, ao atribuir determinados comportamentos às fantasias originárias, Horney, assim como Freud, obscurece o papel da alteridade na constituição psíquica, ponto que nos parece fundamental de afirmar, como base na noção de descentramento proposta por Freud, com a descoberta do inconsciente e que a própria autora afirma em diferentes pontos de sua obra. Isso nos leva a considerar que tais desvios não podem ser explicados à luz de uma temporalidade cronológica, mas, sim, da condição própria do objeto de estudo (o inconsciente), que tem a tendência de fechar-se em si mesmo. Como coloca Laplanche (1997, p. 12):

Certamente, demonstrar um desvio é evidenciar o erro, o caminho errado, mas também é tentar mostrar as causas do desvio, e é aí que as coisas se complicam. Nenhum desvio é inocente, nenhum é desprovido de causa; mas como orientar-se quando é, mais uma vez e de novo, o objeto que é a causa maior do desvio: não só da exigência verdadeira, mas dos desvios e impasses no caminho do verdadeiro?

Poderíamos, como alternativa a essa interpretação da autora, da compulsão à repetição por meio do complexo de Édipo, considerar a identidade, como Lichtenstein (1977), uma performance de automatismos estruturais. E então supor a monogamia como um dos automatismos criados, a partir do "tema de identidade" e implantado durante a situação antropológica fundamental, com a função de recalcamento. Uma vez que, de acordo com o autor, o ser humano, com a evolução, perdeu os genuínos automatismos estruturais, ou instintos, fazse necessária essa repetição de determinados comportamentos, a fim de constituir uma identidade mais ou menos estável, no intuito de nos defendermos da angústia da impermanência, advinda da volatilidade da pulsão. De acordo com Lichtenstein (1977, p. 103):

A compulsão à repetição é uma manifestação da necessidade de manutenção do "tema da identidade". A identidade, nos seres humanos, requer uma "ação repetitiva" para proteger o "imutável dentro da mudança" que acredito ser o aspecto fundamental da identidade humana. [. . .] A manutenção do tema da identidade parece ter prioridade sobre outros princípios, inclusive o princípio do prazer. Eu acredito que Freud, em Além do princípio do prazer, estava consciente de que lidava com problemas de identidade (tradução nossa). ${ }^{6}$

\footnotetext{
${ }^{5}$ De acordo com o autor, o surgimento de padrões sociais e culturais só é possível porque os seres humanos, diferente dos animais, devem definir suas próprias identidades, as quais são, por sua vez, reflexo de sua forma de cuidado simbiótico originário. A mãe, durante os cuidados com a criança, implanta nela um "tema de identidade", o qual é irreversível, mas que é capaz de inúmeras variações, impulsionando a criança a caminhos e meios de concretizar essa identidade que lhe foi impressa.

6 "The repetition compulsion is a manifestation of the necessity of maintenance of the 'theme of identity'. Identity, in man, requires a 'repetitive doing' in order to safeguard the 'sameness within change' which I believe to be a fundamental aspect of identity in man. [.. .] the maintenance of identity theme does indeed appear to have priority over any other principle, including the pleasure principle. I believe, moreover, that Freud, in Beyond the Pleasure Principle, was aware that he was dealing with
} 
Parece-nos que esse tipo de interpretação auxilia a manter a sexualidade como uma alteridade interna, apoiada no corpo, mas não tendo suas origens fixadas no biológico. Percebemos, assim, a oscilação das proposições horneyanas acerca das origens e caminhos percorridos pela sexualidade. Digamos, de passagem, que Lichtenstein é outro autor um tanto esquecido na história da psicanálise, assim como Horney. Citá-lo, neste contexto, serve também para recuperá-lo naquilo que sua teoria traz de reconhecimento das origens alteritárias do sujeito. A interpretação que ele faz da compulsão à repetição, articulando-a à identidade, pode ser concatenada à teoria de Horney e também à de Laplanche, visto que nos ajuda a perceber como questões originárias se apresentam em situações posteriores, como a monogamia ou a identidade de gênero.

Em O ideal monogâmico, por exemplo, Horney (1927) analisa as exigências da monogamia, partindo da exigência de monopólio, à qual associa ao desejo infantil de monopolizar o pai ou a mãe, derivado da fase oral, na qual há o desejo de incorporar o objeto, tornando-se seu único possuidor. Horney, no entanto, ao tentar explicar o ciúme por essa via, recai em um desvio heteronormativo ao colocar que os homens têm um ímpeto mais forte em direção a esse desejo de incorporação, por terem-no realizado parcialmente durante a amamentação, ao passo que as meninas não poderiam voltar-se a nenhuma experiência correspondente em relação ao pai. Ou seja, pelo fato de os meninos viverem a experiência de incorporar o leite, que vem do cuidador do "sexo oposto", alcançando parcialmente o destino dessa pulsão, eles tenderiam a uma maior exigência de monopólio em relação a seu objeto eleito, enquanto as meninas, por não terem tido experiências semelhantes com o cuidador do sexo oposto, não teriam essa mesma tendência. Essa observação da autora deixa explícita sua concepção de uma feminilidade e uma masculinidade primárias, necessariamente heteronormativas. A autora, dessa forma, deixa de fora de sua análise as escolhas de objeto homoafetivas, que poderiam indicar outros caminhos interpretativos. Notamos que, apesar de, no mesmo artigo, Horney atentar para os aspectos sócio-históricos envolvidos nas identificações e escolhas objetais, ela se deixa levar por fortes tendências biologizantes que afetam sua teorização.

Em que pese nossa crítica ao possível desvio heteronormativo, salientamos que a teoria da autora guarda a potência de reconhecer a presença da sexualidade infantil na monogamia. De fato, faz sentido apontar para a importância da amamentação e das primeiras incorporações dos objetos primários como constitutivos da identidade de gênero e os tipos de relaçôes amorosas que esta impõe. 
No mesmo artigo, Horney (1927) associa a exigência de monogamia às pulsões sádico-anais, colocando que o lugar da mulher como um bem móvel demonstra a transformação da exigência de amor em exigência de posse. De acordo com a autora, tais exigências tomam esse aspecto hegemônico por satisfazerem desejos inconscientes, ao mesmo tempo em que contribuem para conquistas nos campos social e cultural:

Esta formação de ideal permite ao ego restringir sua função crítica, que de outra maneira lhe ensinaria que esta reivindicação de monopólio permanente, embora compreensível como desejo, é difícil de se impor e também injustificável como exigência; e, não só isto, ela representa muito mais a satisfação de impulsos narcísicos e sádicos do que indício de desejo de amor verdadeiro. Segundo Rado, a formação deste ideal garante ao ego "segurança narcísica”, sob a qual ele está livre para dar vazão a todas estas pulsões que de outra maneira condenaria e, ao mesmo tempo, crescendo em sua estima por meio do sentimento de que a reivindicação que faz é ideal e justa. [. . .] Além disso, na medida em que a sociedade dá tanta importância à monogamia a, ela tem interesse, do ponto de vista da economia psíquica, em permitir a satisfação dos instintos elementares que fundamentam a exigência, para compensar a restrição que impõe (Horney, 1927, pp. 90-91).

Da mesma forma, a autora explicita o caráter necessariamente pulsional da monogamia, ao afirmar:

Os elementos de ódio encontram saída não só quando se infringe o princípio da monogamia, mas quando ele é obedecido também, e podem vazar de várias maneiras; que os sentimentos de ódio podem ser dirigidos ao parceiro de uma forma ou de outra; e que, de ambos os lados, agem solapando a base em que se apoia a vida de casado - a ternura entre marido e mulher (Horney, 1927, p. 94).

A autora deixa clara, dessa forma, a contribuição clínica de suas análises, que buscam enfraquecer o ideal da monogamia, a partir da compreensão da inevitabilidade dos conflitos existentes quando um casal se forma, ou em qualquer outro tipo de relacionamento entre sujeitos, bem como da dimensão defensiva que um contrato como esse denuncia. Em que pese a escolha permanente de tratar o casal alvo de suas análises como um casal heterossexual, é fácil depreender que, em quaisquer outros arranjos amorosos, os conflitos apontados pela autora, oriundos da sexualidade infantil, estarão presentes.

Ainda no movimento de desconstrução de ideais mantidos socialmente, Horney (1934/1991), em A supervalorização do amor, apresenta um questionamento que parece ainda muito atual acerca do ideal patriarcal de feminilidade, sendo inclusive reproduzido no discurso de analistas, como aponta Ayouch (2014), no qual se coloca que o único desejo da mulher é amar e ser amada por um homem, servi-lo e admirá-lo. A autora denuncia posturas que naturalizam esse lugar de objeto sexual em que a mulher é colocada, afirmando que as interpretações 
nesse sentido ignoram que "os fatores biológicos jamais se manifestam de forma pura e franca, mas sempre modificados pela tradição e o ambiente" (Horney, 1934, p. 181). Como veremos na próxima seção, poderíamos dar mais um passo nessa elaboração crítica, ao situarmos nesse ambiente ao qual Horney se refere a sedução da criança pelo adulto (Laplanche, 1992b), momento no qual a pulsão é implantada ou intrometida na criança mediante mensagens enigmáticas vindas do inconsciente do cuidador. Poderíamos dizer que o cuidado prestado pelos adultos às meninas está impregnado dessas mensagens bem como de traduções possíveis a tais mensagens, tal como o ideal de feminilidade supracitado.

Horney (1932) aponta que os problemas que podem surgir em um relacionamento, como o casamento, têm origem muito mais profunda do que meras desavenças ou discordâncias entre parceiros, sendo frutos de conflitos não resolvidos durante nosso próprio desenvolvimento. A autora afirma ainda que tais conflitos são, muitas vezes, inevitáveis, mas que suas consequências podem ser superadas ou atenuadas, sendo o ponto ótimo de um relacionamento o equilíbrio entre concessões e privações (Horney, 1932). Nesse sentido, Horney enfatiza a necessidade de avaliar o padrão absoluto da monogamia, uma vez que nem todos serão capazes de adaptarem-se às restriçôes e liberdades que esse tipo de relacionamento impóe.

Teríamos que renunciar aos direitos a formas diferentes de busca e encontrar satisfação de outros impulsos existentes dentro de nós mesmos que o parceiro deixa insatisfeitos. Em outras palavras, é preciso rever seriamente o padrão absoluto da monogamia, examinandolhe, sem preconceitos, origem, valores e perigos (Horney, 1932, p. 129).

Dessa forma, é possível perceber que a monogamia, como arranjo, funciona como obstáculo para a satisfação imediata da pulsão e é utilizada pelos sujeitos de forma essencialmente singular, devendo ser transcendida tanto em sua dimensão sociológica quanto psicológica. Assim, o campo da interpretação, inclusive a interpretação dos fenômenos sociais, deve ser ampliado, levando-se em consideração o caráter disruptivo, demoníaco e típico da pulsão sexual de morte, da mesma forma que as saídas defensivas dos sujeitos para essa pulsão. 


\section{APORTES DA TSG SOBRE AS QUESTÕES DE GÊNERO}

Como colocado na introdução deste trabalho, ao tentarmos aprofundar nossos conhecimentos a respeito das relaçóes amorosas, como se configuram e quais as causas e consequências que as rodeiam, é imprescindível que se faça, também, uma elaboração acerca das questôes identificatórias e de gênero, que invariavelmente afetam nossas formas de nos relacionarmos.

Laplanche (2015b) traz questionamentos interessantes a respeito da atual tendência de substituir o termo "identidade sexual" por "identidade de gênero". $\mathrm{O}$ autor questiona se essa mudança não estaria a serviço do recalque do que ele optou por chamar de sexual (atendo-se à grafia em alemão para designar o sexual ampliado, ao qual Freud se referia). O autor, no entanto, opta por manter o conceito de gênero na Psicanálise, uma vez que, de acordo com suas observações, essa concepção já estava presente em Freud, nas entrelinhas. Para a finalidade deste artigo, cabe a exposição de sua teorização a respeito dos conceitos de gênero, sexo e sexual, a fim de que se torne ainda mais claro o quão comprometidas nossas escolhas amorosas estão com o inconsciente.

De acordo com o autor, e diferente da maior parte das teorias sobre gênero, inclusive as feministas, "o gênero precede o sexo. Mas, ao invés se organizá-lo, é organizado por ele" (Laplanche, 2015b, p. 168). Nesse mesmo artigo, Laplanche coloca que as mensagens de designação do gênero, advindas do socius que circunda a criança (pais, irmãos, avós, etc.), são comprometidas pelos "ruídos" (Laplanche, 2015b, p. 168) causados pelo inconsciente dos adultos. Ou seja, além da comunicação veiculada através dos cuidados corporais, há o código social ao qual todos estamos submetidos, devido à nossa situação antropológica fundamental (Laplanche, 2015b).

Dessa forma, a designação de gênero chega à criança, muito precocemente, de maneira enigmática, cabendo ao sexo traduzir, fixar o gênero durante o segundo ano da criança, aproximadamente. Seria, então, a diferença anatômica de sexo o destino, concordando com Freud. Laplanche ressalta, no entanto, que essa anatomia não corresponde à biologia. É, antes, a anatomia "popular" que se configura como destino pulsional. Essa observação se torna extremamente importante devido à consequência imediata de que, no ser humano, devido à sua condição bípede, a percepção dos órgãos genitais é, na verdade, a percepção de "um" órgão genital, o masculino, sobre o qual é estruturada toda uma linguagem. De acordo com Laplanche (2015b):

A diferença anatômica perceptiva é uma linguagem, um código? Certamente não é um código completo, mas, no mínimo, é o que estrutura um código, um código dos mais 
rígidos, estruturado justamente pela lei do terceiro excluído, pela presença/ausência. É antes o esqueleto de um código, mas de um código lógico, que eu tenho designado, há muito tempo, como "lógica fálica" (p. 171). ${ }^{7}$

Com base nessa leitura de Laplanche, é possível ver na anatomia um código a ser interpretado e não um destino biológico preciso, imutável. Amplia-se, dessa forma, o campo das simbolizações possíveis a essas mensagens designatórias. Ao questionar a lógica fálica, a lógica do terceiro excluído, Laplanche (2015b) visa a flexibilizar os modelos de simbolização, explicitando-os como ambivalentes e múltiplos.

\section{APROXIMAÇÕES ENTRE LAPLANCHE E HORNEY}

Da mesma forma, Horney, aparentemente, entende que gênero e identidade não são colados, não correspondem, mas vacila em alguns pontos a esse respeito. Ao apresentar apenas exemplos em que identidade e gênero correspondem, deixando de lado, por exemplo, as escolhas homoafetivas, dando a entender que os problemas do amor são problemas da questão heterossexual e preterindo, mais uma vez, a ideia de código, a favor da concepção da "grande força de atração heterossexual". A esse respeito, Laplanche (2015b) reforça que a gênese do gênero é independente da gênese da escolha de objeto, relembrando a fórmula freudiana da homossexualidade, a partir do caso de Leonardo da Vinci. Ele afirma que "Leonardo - ama - um menino à imagem de Leonardo criança. Leonardo, no entanto, não é identificado ao gênero da mãe, mesmo tomando seu lugar" (Laplanche, 2015b, p. 177).

Horney (1927), em alguns momentos, mostra que está atenta para o fato de existirem interpretaçóes que visam a recalcar, em vez de explicitar o caráter mortífero e polimorfo da pulsão, ao explicar a supervalorização do amor conjugal mediante o empenho das pessoas em se responsabilizarem pelas exigências psíquicas do casamento, como uma "necessidade de síntese com a qual estamos acostumados no ego e à qual podemos atribuir a falsificação dos fatos com o intuito de demonstrar atitude ingênua em relação tão importante na vida” (Horney, 1927, p. 85).

A autora afirma que, na verdade, o voto de fidelidade matrimonial é uma repetição dos votos inconscientes realizados na primeira infância para os pais, como primeiros objetos de amor. Da mesma forma, explicitando as múltiplas formas tradutivas, Horney (1937/1991) questiona a generalidade do Édipo,

\footnotetext{
${ }^{7}$ Laplanche (1988) utiliza o termo "lógica", a fim de explicitar o caráter polarizado, representado por pares de opostos, de cada fase do desenvolvimento sexual proposto por Freud. A fase em questão caracteriza-se pela oposição fálico/castrado.
} 
situando-o como uma resposta à "influência de pais neuróticos" (p. 255), o que estaria de acordo com a proposição laplancheana de uma "história traduzida em Édipo" (Laplanche, 2015a, p. 286). Em outras palavras, conceber o Édipo como esquema narrativo, e não como um código, parece corresponder melhor aos fenômenos que percebemos na clínica, às variáveis mais ou menos complexas e elaboradas que os analisandos apresentam diante das experiências infantis com os cuidadores.

Percebemos, assim, um movimento duplo da autora que, ao mesmo tempo em que reconhece o caráter intrinsecamente conflitivo do inconsciente, como quando afirma:

Quanto maior a compreensão da inevitabilidade desses e de outros conflitos em qualquer casamento, mais profunda será a convicção de que nossa atitude quanto a essas impressóes pessoais não comprovadas [de que a única saída para o conflito matrimonial é o divórcio] deva ser de total reserva, e maior será nossa capacidade de controlá-las (p. 95).

Também coloca o Édipo como fundo onipresente de todos os relacionamentos amorosos, acreditando que, ao tornar o casamento mais flexível, os conflitos seriam neutralizados. "O casamento pode ter um prognóstico infeliz desde o início se não escolhermos o parceiro 'certo"” (Horney, 1932, p. 119). Assim, ela pressupóe que se pode ter um casamento mais feliz, menos conflituoso se encontra-se o parceiro certo, ou seja, aquele que não supre apenas uma necessidade isolada do sujeito.

Existe, sim, uma teoria do amor, que sustenta a construção de arranjos amorosos, escolhas de parceiros que podem ser mais ou menos conflituosas, tratada pela psicanálise, mas insistimos com Laplanche, e talvez com a Horney de 1927 e de 1934, que não há, no entanto, qualquer arranjo que seja capaz de fazer uma neutralização do sexual, por mais "certo" que seja o parceiro. Entendemos que o resultado esperado da análise, neste âmbito, seja a escolha de parceiros que produzam menos situações mortíferas para o sujeito, como nas fantasias infantis de posições demasiadamente masoquistas e de muito sofrimento.

Demonstrando suas percepções vanguardistas, ainda no artigo de 1927, Horney exemplifica, em relação às mulheres, uma dificuldade que podem levar ao casamento, que seria a frigidez, ou a incapacidade de entregar-se a um homem. A autora interpreta tal sintoma como resultante da rejeição de um homem ou do sexo masculino em geral. Podendo expressar-se no afastamento do parceiro através de seu "ciúme, exigências, cansaço e rabugices" (Horney, 1927, p. 125). De acordo com Horney, a angústia advinda da assunção do papel feminino, no sentido da passividade, pode provocar desvios no sentido de uma fuga para a masculinidade ou mesmo na fixação por um filho, deixando o relacionamento 
conjugal de lado. Horney deixa implícito, portanto, que sexo e gênero não correspondem naturalmente. $\mathrm{O}$ desconforto na assunção do papel feminino e a fuga para a masculinidade demonstram exatamente isso.

Percebemos que existe uma psicologia do amor em Karen Horney, a qual descreve os elementos psíquicos de homens e mulheres que estão em jogo nos relacionamentos íntimos, bem como suas origens infantis e que paga muitos tributos ao esquema narrativo edípico, mas não o questionando como arranjo recalcante do pulsional. Os textos da autora, com frequência, tratam o Édipo heterossexual como a fonte do conflito psíquico. A sexualidade infantil, o pulsional, o inconsciente mais disruptivo avesso às reduções codificadas, não aparecem. Parece-nos que insistir muito nesses esquemas não somente reforça que eles são a norma, que são "naturais", como também impede que compreendamos que as múltiplas defesas produzem múltiplas possibilidades de amar e de ser amado.

\section{CONSIDERAÇÕES FINAIS}

A tarefa de recuperar uma autora esquecida ao longo da História da Psicanálise tem resultados epistemológicos e políticos importantes. Pensar na História da Psicanálise como um todo, como a história de uma exigência de reconhecimento do inconsciente como alteridade irredutível, permite ler a promoção ou o apagamento de autoras e autores como movimentos que aproximam ou distanciam a teoria de sua exigência fundamental.

O inconsciente como alteridade sexual, irredutível a qualquer tradução consciente, o que faz o eu ser descentrado de seu lugar soberano; fazer trabalhar essa exigência epistemológica é um dos elementos da revolução copernicana inacabada (Laplanche, 1992a). Inacabável também, podemos dizer, pois, como vimos no caso desse tipo de exumação teórica feita com a obra de Horney, outras portas se abrem, outras suspeitas, além de deixar claro que o próprio corpo examinado traz elementos contrários à exigência buscada.

Importante destacar que essa tarefa histórico-epistemológica também rende frutos políticos e clínicos importantes. No caso do exame da monogamia em Horney, podem-se ver críticas feministas importantes que nos ajudam a desconstruir os arranjos heteronormativos como sendo naturais e imutáveis. Tal desconstrução instrumenta a/o analista a ver relações amorosas, tais como Laplanche nos convida: como resultados de traduções do sexual. Traduções que se valem de códigos e narrativas estáveis e estabilizadoras da subjetividade. Reconhecer a natureza contingencial desses arranjos é precondição para buscar 
novas traduções, menos comprometidas com os aspectos infantis e mortíferos de cada um. 


\section{REFERÊNCIAS}

Abraham, K. (1920, September). Manifestations of the female castration complex. International Journal of Psychoanalysis, 3, 1-29.

Appignanesi, L., \& Forrester, J. (2010). A questão da feminilidade. In As mulheres de Freud. (pp. 573-678). Rio de Janeiro: Record.

Ayouch, T. (2014). Sex difference in psychoanalytical theory: aporiae and deconstructions. Revista Brasileira de Psicanálise, 48(4), 58-72.

Belo, F. R., \& Marzagão, L. R. (2011). Sobre o amor. In Sobre o amor e outros ensaios de psicanálise e pragmatismo. Belo Horizonte: Ophicina de Arte \& Prosa.

Garrison, D. (1981). Karen Horney and feminism. Signs, 6(4), 672-691.

Horney, K. (1923/1991). A gênese do complexo de castração nas mulheres. In T. Rodrigues (Trad.), Psicologia feminina. (pp. 35-50). Rio de Janeiro: Bertrand Brasil, 1991. (Publicado originalmente em 1923).

Horney, K. (1926/1991). A fuga da feminilidade. In T. Rodrigues (Trad.), Psicologia feminina. (pp. 51-66). Rio de Janeiro: Bertrand Brasil, 1991. (Publicado originalmente em 1926).

Horney, K. (1927/1991). O ideal monogâmico. In T. Rodrigues (Trad.), Psicologia feminina. (pp. 81-96). Rio de Janeiro: Bertrand Brasil, 1991. (Publicado originalmente em 1927).

Horney, K. (1932/1991). Os problemas no casamento. In T. Rodrigues (Trad.), Psicologia feminina. (pp. 117-129). Rio de Janeiro: Bertrand Brasil, 1991. (Publicado originalmente em 1932).

Horney, K. (1933/1991). A negação da vagina. In T. Rodrigues (Trad.), Psicologia feminina. (pp. 145-158). Rio de Janeiro: Bertrand Brasil, 1991. (Publicado originalmente em 1933).

Horney, K. (1934/1991). A supervalorização do amor. In T. Rodrigues (Trad.), Psicologia feminina. (pp. 181-210). Rio de Janeiro: Bertrand Brasil, 1991. (Publicado originalmente em 1934).

Horney, K. (1937/1991). A necessidade neurótica de amor. In T. Rodrigues (Trad.), Psicologia feminina. (pp. 243-256). Rio de Janeiro: Bertrand Brasil, 1991. (Publicado originalmente em 1937). 
Kurzweill, E. (2000). A receptividade a Freud nos Estados Unidos. In V. Ribeiro (Trad.), Freud: conflito e cultura: ensaios sobre sua vida, obra e legado. (pp. 116126). Rio de Janeiro: Jorge Zahar.

Laplanche, J. (1978). Interpretar [con] Freud. J. A. Zarza (Trad.). Buenos Aires: Nueva Visión.

Laplanche, J. (1988). Castração: seus precursores e seu destino. In Problemáticas II: castração/simbolizações. A. Cabral (Trad.). (pp. 1-148). São Paulo: Martins Fontes.

Laplanche, J. (1992a). La revolution copernicienne inachevée. Paris: Aubier.

Laplanche, J. (1992b). Problemáticas IV: o inconsciente e o id. A. Cabral (Trad.). São Paulo: Martins Fontes.

Laplanche, J. (1997). Freud e a sexualidade: o desvio biologizante. L. Magalhães (Trad.). Rio de Janeiro: Jorge Zahar, 1997.

Laplanche, J. (2015a). Castração e Édipo como códigos e esquemas narrativos. In V. Dresch, \& M. Marques (Trad.), Sexual: a sexualidade ampliada no sentido freudiano. (pp. 281-287). Porto Alegre: Dublinense.

Laplanche, J. (2015b). O gênero, o sexo e o sexual. In V. Dresch, \& M. Marques (Trad.), Sexual: a sexualidade ampliada no sentido freudiano. (pp. 154-189). Porto Alegre: Dublinense.

Lichtenstein, H. (1977). Idenity and sexuality. New York: Jason Aronson.

Paris, B. J. (1994). Karen Horney: a psychoanalyst's search for self-understanding. New Haven: Yale University Press.

Reyes, V. O. (2002). Karen Horney, pionera de la ruptura con el modelo freudiano para explicar la psicología femenina y el desarrollo humano sano y neurótico. Apuntes de Psicología, 20(2), 307-322.

Roudinesco, E., \& Plon, M. (1998). Dicionário da Psicanálise. V. Ribeiro, \& L. Magalhães (Trads.). Rio de Janeiro: Zahar.

Silva, D. Q., \& Folberg, M. N. (2008). De Freud a Lacan: as ideias sobre a feminilidade e a sexualidade feminina. Estudos de Psicanálise, 31, 50-59. Recuperado a partir de http://pepsic.bvsalud.org/scielo.php?script=sci_ arttext\&pid=S0100-34372008000100007\&lng=pt\&tlng=pt 
Valdivia, O. B. (1997). Psicanálise e feminilidade: algumas considerações. Psicologia: Ciência e Profissão, 17(3), 20-27. 